\title{
A AVENIDA SETE DE SETEMBRO EM CÁCERES-MT: HISTÓRIA E MEMÓRIA.
}

\author{
'Leandro de Almeida \\ Mestre em Ciências das Religiões \\ leandrohis@gmail.com
}

\section{RESUMO}

Nas últimas décadas o estudo das cidades tem se tornado um dos principais interesses de pesquisadores principalmente no tocante aos usos que os moradores fazem destes espaços. Nesta perspectiva a cidade é um espaço privilegiado de pesquisa, pois a mesma apresenta em suas ruas, prédios públicos, lojas, repartições, ou seja, uma infinidade de memórias marcadas por acontecimentos que deixaram muitas lembranças. Utiliza-se como meio para compreensão dessas transformações ocorridas nesse espaço em Mato Grosso especificamente na cidade de Cáceres, reportagens, revistas, bibliografia, monografias que tratam especificamente dessas mudanças ocorridas na cidade. Assim nos utilizamos das fontes escritas, iconográficas e orais de alguns personagens que vivenciaram de forma mais direta esta parte da cidade. Dentre as fontes escritas podemos destacar a revista do bicentenário da cidade ocorrido no ano de 1978 na qual apresenta alguns indicativos do desenvolvimento da cidade no final desta década e que foi muito importante para as reflexões deste artigo. Quanto às fontes Iconográficas, estas foram muito importantes para mostrar ao leitor alguns dos principais pontos comerciais da avenida ao mesmo tempo em que serviram de suporte para muitas de nossas reflexões. Claro que na busca pela compreensão deste objeto encontram-se algumas questões que estão relacionadas à ideia de progresso, porém vou me limitar apenas em tentar reproduzir as transformações ocorridas nesse espaço tão frequentadas por usuários na cidade de Cáceres, tentarei apresentar como essas mudanças influenciaram o imaginário da população cacerense da época.

Palavras chave: Avenida Sete de Setembro, Mudanças, Cidade, Comercio 


\section{ABSTRACT}

In recent decades the study of cities has become one of the main interests of researchers particularly with regard to the uses that residents make these spaces. In this perspective the city is a special area of research because it presents in its streets, public buildings, shops, offices, or a multitude of memories marked by events that have left many memories. It is used as a means for understanding these transformations in this space in Mato Grosso specifically in the city of Cáceres, reports, magazines, literature, monographs that deal specifically with these changes in the city. Thus the use of written, oral and iconographic sources of some characters who have experienced more directly this part of town. Among the written sources we can highlight the city's bicentennial magazine occurred in 1978 in which it provided some indications of city development at the end of this decade and that was very important for the reflections of this article. As for Iconographic sources, these were very important to show the reader some of the main commercial avenue while that served as support for many of our reflections. Of course, in seeking to understand this object are some issues that are related to the idea of progress, but I will limit myself just try to play the changes occurring in that space as frequented by users in the city of Cáceres, try to present how these changes have influenced the imagery of Cacerense population of the time.

KEYWORDS: Sete de Setembro Avenue , Changes, City, Commerce 


\section{INTRODUÇÃO}

Nas ruas e avenidas das grandes cidades do país encontramos quase sempre algumas características marcantes que se apresentam através dos seus monumentos, dos seus edifícios ou, talvez, uma variação que as tornam diferentes das demais. Michel de Certeau ao apresentar Nova lorque de cima dos antigos arranha-céus World Trade Center (derrubados pelos aviões no dia 11 de setembro de 2001), nos mostra a vastidão de uma cidade que se estende por quilômetros até perder de vista, mas ao mesmo tempo, este historiador coloca toda esta imensidão em um segundo plano, ao privilegiar os usuários da cidade que perambulam por suas avenidas, ruas e becos. São eles os "organizadores" da cidade, são eles que fazem à cidade.

Partindo desta ideia, Cáceres, em seus 235 anos, apresenta alguns espaços no seu traçado urbano que vão além de sua materialidade exterior como a Avenida Sete de Setembro. Esta, ao longo de sua existência sofreu inúmeras transformações em seu traçado e em sua organização e, sobretudo, nos usos que os moradores da cidade fazem dela. O que era um antigo caminho que levava os moradores ao Cemitério São João Batista, na segunda metade do século XIX, transformou-se em movimentada avenida com lojas, postos de gasolina, um hospital e até a antiga rodoviária da cidade.

Essas mudanças ocorridas neste espaço constituem o tema deste trabalho. O objetivo é mapear estas transformações ligando-as a outros acontecimentos que, em nossa interpretação, foram fundamentais para que isto ocorresse. Adjacente a esta preocupação, faremos um percurso pelas principais transformações que ocorreram na avenida, concentrando nossas atenções na questão da arborização que se tem ao longo de toda a Avenida.

O presente artigo está desenvolvido em dois momentos. No primeiro, damos destaque ao surgimento e desenvolvimento da avenida como um espaço social e econômico da cidade. Nesse sentido, recuperaremos a constituição histórica deste espaço desde as primeiras referências documentais até os estabelecimentos da avenida como parte integrante da zona comercial da cidade, além de importante elo entre as zonas leste-oeste da cidade. Como isso, procuramos estabelecer um paralelo entre um lugar de referência comercial e o próprio desenvolvimento da cidade. Uma importante referência para esta reflexão foi à dissertação de mestrado de Adson de 
Revista Eletrônica História, Natureza e Espaço - ISSN 2317-8361 v. 3, n. 1 (2014)

Arruda $^{1}$ e o livro da autora Ana Fani A. Carlos (2004), Novos escritos sobre a cidade 2. Os trabalhos que analisamos ambos enfatizam a questão das cidades nos quais procuram percebê-las como espaços constituídos por seus usuários.

No segundo momento abordamos as mudanças ocorridas ao longo do seu traçado. Tendo como foco o modo pelo qual foram estabelecidas essas mudanças. Também procura-se investigar como estes "frequentadores" assíduos deste espaço imaginam o lugar. É importante lembrar que a atual Avenida Sete de Setembro não adquiriu esta condição no período estudado, pois há muito esta tem sido um espaço de comercialização de produtos, sobretudo, dos pequenos produtores da região que se estabeleciam sazonalmente na avenida para comercializar os seus produtos e que atraíam inclusive pessoas de outras localidades próximas para comprarem víveres e outras necessidades.

\section{A AVENIDA SETE DE SETEMBRO EM CÁCERES: DIVERSOS OLHARES}

Para falarmos da Avenida Sete de Setembro, com seu traçado retilíneo e espaçoso, é importante ressaltar que desde a fundação da cidade de Cáceres, quando o Capitão General da Capitania de Mato Grosso, Luiz Albuquerque de Melo Pereira e Cáceres, em 1778, ordenou a edificação da cidade que recebeu o nome de Vila Maria do Paraguai, em homenagem à rainha de Portugal D. Maria I, na qual foram colocados todos os preceitos racionais de construção de cidades portuguesas da época. Ou seja, privilegiou-se sua forma retilínea com ruas principais e secundárias, tendo como centro uma praça onde se localizaria o poder temporal e espiritual. Segundo Adson de Arruda:

Ao elegermos a cidade como objeto de estudo, nos aproximamos da historiografia especializada que afirma serem as cidades 'espaços' que ligam os indivíduos e os grupos e em suas práticas sociais. Esses 'espaços', por sua vez, não podem ser concebidos apenas a partir de conceitos urbanísticos ou políticos, mas como o lugar da pluralidade das diferenças sociais (ARRUDA 1998; 124 p)

Dessa forma, o nosso estudo pretende percorrer esses "espaços" da cidade, mas exclusivamente os espaços da Avenida Sete de Setembro e

\footnotetext{
${ }^{1}$ ARRUDA, Adson de. Imprensa, vida urbana e fronteira: A cidade de Cáceres nas primeiras décadas do século xx (1900-1930).

2 CARLOS, Ana Fani Alessandri. O espaço urbano: Novos escritos sobre a cidade. 2 ed. São Paulo: Contexto, 2004.
} 
observar as transformações e a pluralidade das diferenças sociais na cidade. Ainda, segundo o mesmo autor:

As relações sociais desenvolvidas nas cidades são historicamente determinadas, capazes de fornecer elementos para a compreensão das atitudes, desejos e projetos de homens e mulheres em épocas distintas. Captar e investigar as práticas sociais e comportamentos dos moradores de uma cidade implica em dar visibilidade aos vários projetos que colocam em curso, tais como os modos de viver, de morar, de lutar, de trabalhar e se divertir dos moradores (ARRUDA 1998).

Isso quer dizer que através das relações desenvolvidas na avenida sejam elas sociais, culturais e até mesmo estruturais, é possível fornecer elementos para a compreensão das atitudes das pessoas que se interligam com a avenida. A cidade e suas transformações fornecem elementos para a compreensão do cotidiano e das transformações e práticas que são uma constante nesses espaços.

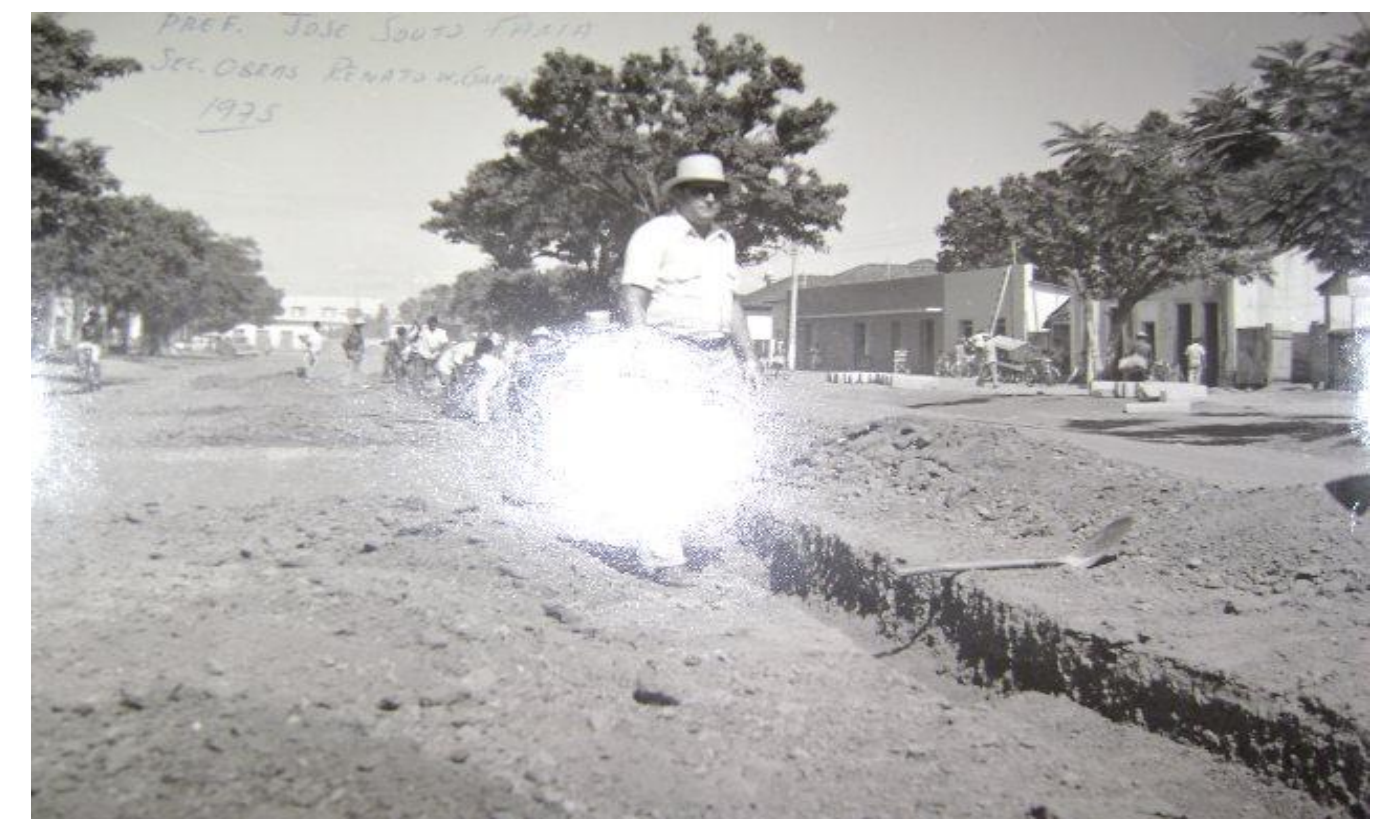

Foto 1 - A avenida no início da pavimentação.

Fonte Museu Municipal de Cáceres-MT

Através de uma entrevista realizada no mês de maio, deste ano de 2013, com Miguel Samattore, um senhor de 63 anos, morador há mais de 50 na cidade de Cáceres, e que participou desse processo de urbanização da cidade de Cáceres, foi possível perceber em seu relato, indícios sobre a transformação do espaço da avenida.

Nas descrições sobre a cidade presentes em sua narrativa, notamos o quanto suas impressões são fundamentais para a compreensão deste estudo, pois através da sua memória procuramos encontrar evidencias que nos revele pistas para o porquê 
Revista Eletrônica História, Natureza e Espaço - ISSN 2317-8361 v. 3, n. 1 (2014)

dessas transformações ao longo dos anos da Avenida Sete de Setembro. Sem a preocupação de mudar o pensamento do morador destacamos aqui a importância da Avenida Sete de Setembro para o crescimento e fortalecimento da economia de Cáceres.

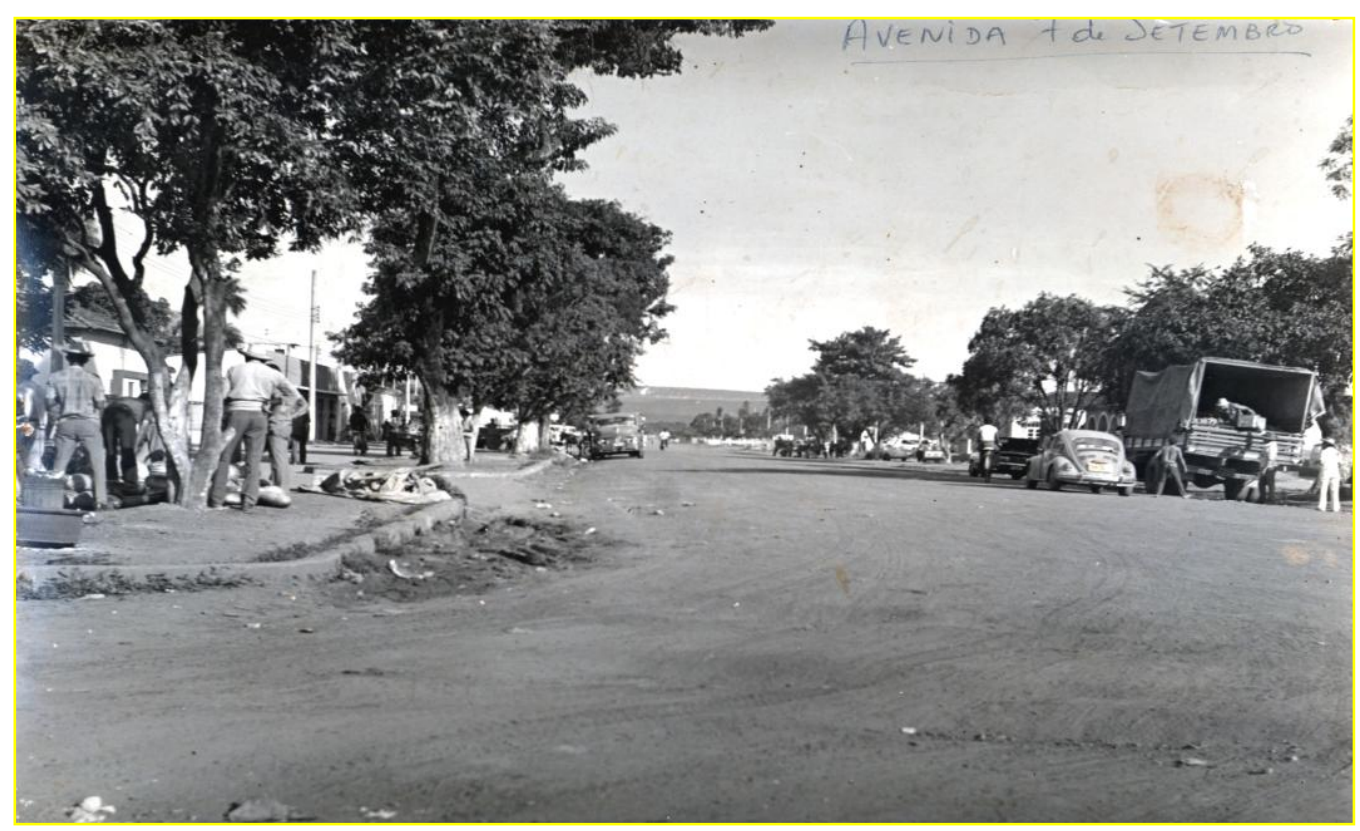

Foto 2 - Avenida Sete de Setembro na Década de 70.

Fonte: Arquivo Particular - Adilson Reis - Cáceres/MT.

As pistas laterais não existiam, somente uma espécie de pátio, onde havia um mínimo de acessos aos pouquíssimos prédios que eram percorridos através de passagens de pontes e tijolos sobre as valas ou uma pinguela que dava entrada ao colégio que funcionava na década de 1970. Com a pavimentação da avenida, houve um incremento nas práticas comerciais de produtos. Os principais produtos comercializados na década de 70 eram oriundos da agricultura na região da grande Cáceres. Na avenida, os comerciantes comercializavam produtos como arroz, feijão, carne, milho, galinhas entre outros. O que era produzido na zona rural, os agricultores traziam para vender ou trocar na cidade.

Cáceres, com o tempo, passou a ser considerado um polo comercial para as regiões vizinhas. Os municípios desmembrados como Mirassol D’Oeste, São José dos Quatro Marcos, Rio Branco entre outras, recorriam a cidade de Cáceres para fazerem 
Revista Eletrônica História, Natureza e Espaço - ISSN 2317-8361 v. 3, n. 1 (2014)

suas compras e procurarem recursos médicos. O senhor Rosalvo Carneiro, outro entrevistado afirma que:

"Naquela época as compras eram feitas em sua grande maioria aqui mesmo no município de Cáceres. Tornando o fluxo comercial mais intenso e bem mais concorrido na década de 1980 que atualmente" ${ }^{3}$.

Nessa época, de 1950, no lado direito da avenida existia a igreja Perpétuo Socorro e os salões utilizados pela escola. Existiam também a residência do pecuarista Nestor Silva, enquanto que do lado esquerdo o Hospital São Luis. Este pode ser considerado como o prédio mais antigo da avenida e de grande importância para cidade em si. Atualmente o hospital é um prédio imponente no coração da cidade ${ }^{4}$.

No ano de 1940, data da construção do prédio onde atualmente é o Hospital São Luiz, é importante destacar que havia uma ou duas casas de adobes e o único posto de gasolina da cidade que pertencia ao senhor Jair de Oliveira Garcia, onde existia uma pequena casa, uma bomba de gasolina e quase sempre filas de uns dez a quinze tambores de aço, latas, aguardando o combustível que dificilmente chegava em Cáceres.

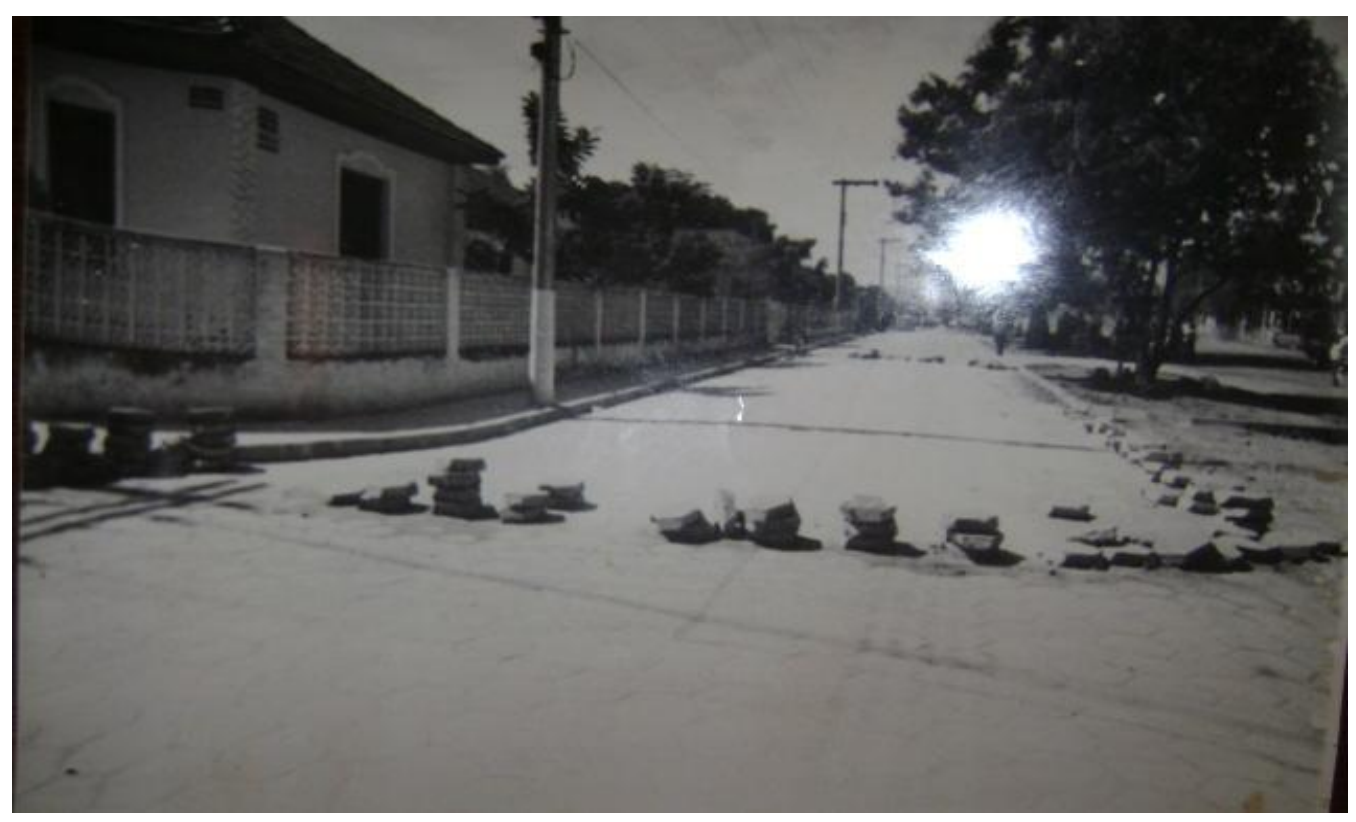

Foto 3 - Hospital São Luis na década de 1970.

Fonte Museu Municipal de Cáceres-MT

\footnotetext{
${ }^{3}$ Entrevista realizada no dia 20 de abril 2013

${ }^{4}$ Faz frente com as lojas Destak Confecções, Casa do Alumínio e Brasil América.
} 
O movimento de veículos apesar de ser a saída para a capital era quase nenhum; frequentemente via-se transitar carros de bois ou carros de burros com pessoas que traziam produtos tais como, arroz, feijão, milho, galinha, carne de boi, vindo da Morraria.

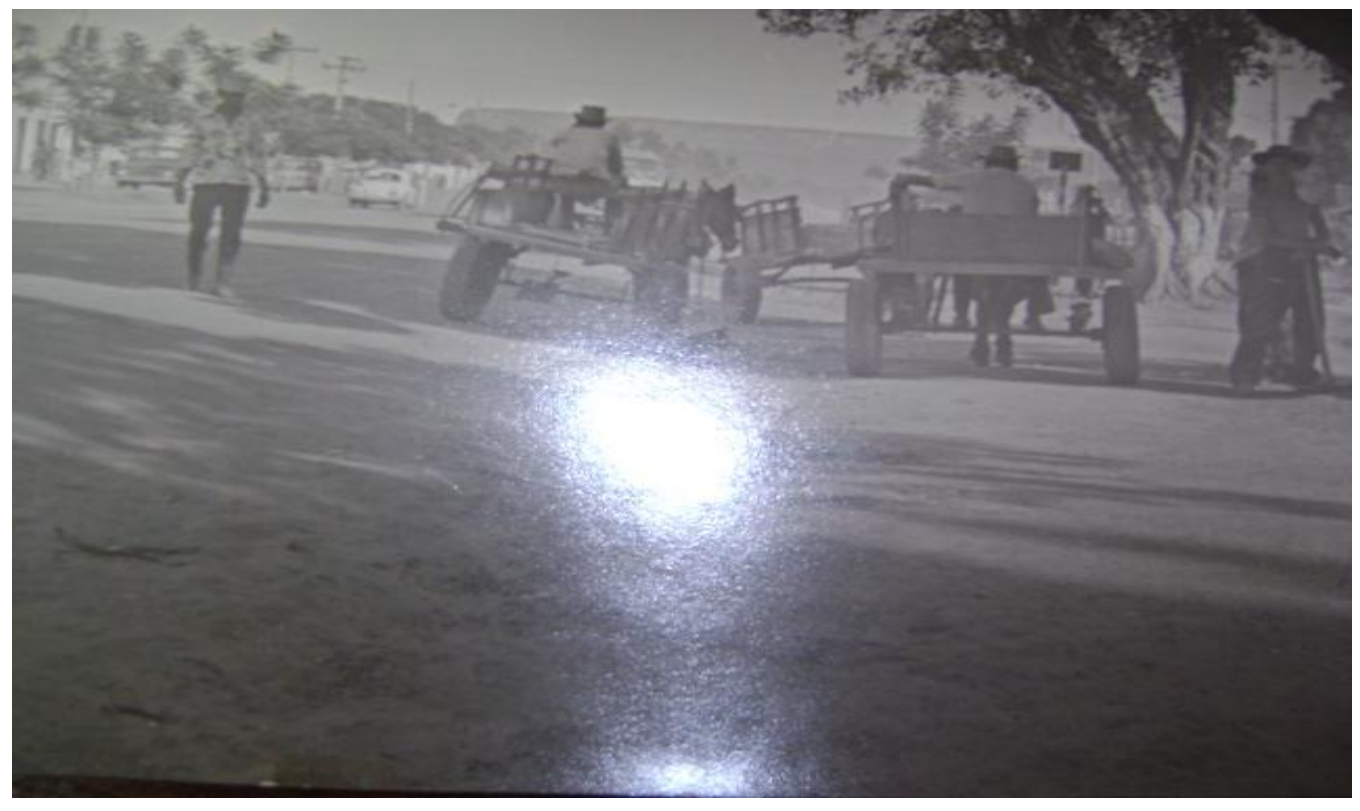

Foto 4 - Meio de locomoção dos produtos.

Fonte: Museu Municipal de Cáceres-MT

Foi possível identificar a partir da fala do senhor Miguel Senatore que, nesse período da década de 60 , era muito difícil a comercialização de produtos aqui em Cáceres, pois a cidade se encontrava em processo de crescimento e fortalecimento de sua economia. Nesse sentido, os produtos vinham da Região de Morraria, considerada como a pioneira, no que diz respeito ao fornecimento de produtos agrícolas para Cáceres, produtos esses que se estabeleciam através de trocas de mercadoria. Um dos exemplos que podemos destacar dessa relação é dos produtores de arroz que trocavam seus produtos por outros alimentos de sua necessidade. Na maioria das vezes esses produtos eram trazidos de carroça, um dos principais meios de locomoção utilizados pelos comerciantes da época. Com a pavimentação da Avenida Sete de Setembro esses comerciantes de produtos agrícolas começaram, então, a ter um acesso mais rápido a cidade.

O cemitério, por exemplo, é um espaço da avenida que chama a atenção. Ele marca a passagem para a outra vida. No início da construção da avenida ela era um caminho que conduzia a esse espaço. O cemitério era o destaque, ou melhor, o marco do caminho que levava as pessoas para se despedirem dos entes queridos que 
Revista Eletrônica História, Natureza e Espaço - ISSN 2317-8361 v. 3, n. 1 (2014)

morriam. Com o tempo e crescimento da cidade, o cemitério já não exerce tanta influência assim. Apesar de ainda ocupar um lugar de destaque na avenida outros estabelecimentos hoje dividem essa atenção.

Nesse sentido, com o aumento populacional de Cáceres na década de 1980, a integração através das migrações internas vindas das regiões sudeste do país, construção e mudança da capital nacional para a região Centro Oeste do país, bem como a construção da ponte Marechal Rondon sobre o rio Paraguai na década de 50, são alguns dos fatores que proporcionaram o crescimento da cidade. Essas melhorias, e em caráter especialmente local, a melhoria do antigo aeroporto denominado Manoel Cuiabano, a construção do Terminal Rodoviário no Centro, foram motivos que reorganizaram as práticas e relações comerciais na Avenida Sete de Setembro.

Face aos fatores acima citados aqui nesse trabalho podemos destacar que, incrementa-se no Centro de Cáceres o novo e atual visual, desta vez com tecnologia, planejamento, para a configuração da atual avenida, com pistas pavimentadas de asfalto que simbolizam o progresso.

Utilizando-se das representações que Chartier discorre sobre as cidades, Arruda afirma que:

Os vários discursos sobre a cidade, portanto, não podem ser pensados como referências verdadeiras que se impõem de forma natural, porque são 'produtos das relações sociais desenvolvidas na cidade que em última análise, acabam por definir e delinear a paisagem urbana, a imagem da cidade'. Desse modo, as relações sociais desenvolvidas nas cidades são historicamente determinadas, capazes de fornecer elementos para a compreensão das atitudes, desejos e projetos de homens e mulheres em épocas distintas. Captar e investigar as práticas sociais e comportamentos dos moradores de uma cidade implica em dar visibilidade aos vários projetos que colocam em curso, tais como os modos de viver, de morar, de lutar, de trabalhar e se divertir dos moradores (ARRUDA 1998:06)

Ao observar esses espaços urbanos, as multiplicidades das relações sociais que são desenvolvidas na cidade, podemos pensar a avenida em destaque como um local de práticas e comportamentos distintos. A avenida, não por acaso, é localizada no centro e engloba os principais agentes da sociedade.

Outro fator que podemos considerar como uma inovação nas práticas desse comércio da avenida, foi o avanço tecnológico utilizados pelas lojas comerciais. Sendo assim, iniciava-se uma nova fase de relações comerciais no município de Cáceres, 
Revista Eletrônica História, Natureza e Espaço - ISSN 2317-8361 v. 3, n. 1 (2014)

incorporando outras práticas no quotidiano dos empresários locais. Quanto aos consumidores estes tiveram que se adaptar ao novo sistema de compra e venda em que, segundo Paula Sibília ${ }^{5}$, predomina uma tendência generalizada de abstração e virtualizaçao dos valores.

O novo lugar agora com traços de modernidade simboliza, para a população de Cáceres, um importante local para as suas compras, pois o comércio da atual Avenida Sete de Setembro é constituído de farmácias, supermercado, posto de gasolina, lojas de móveis, lojas de roupas, entre outros ramos de atividades comerciais. Assim, a avenida basicamente tem todos os itens que o consumidor procura, a ideia de comodidade e, sobretudo, ganhar tempo na hora de efetuaram suas compras, entre outros fatores contribuíram para o fortalecimento do comércio daquela região. Podemos visualizar um espaço de atividades que pode ser considerado um lugar onde circula grande fluxo de pessoas, em grande parte, devido a esses fatores aqui já mencionados.

Vale ressaltar que devido a esses fatos, a avenida tornou-se hoje, um dos espaços físicos mais usados pelos cacerenses, pois ali se encontra uma grande quantidade de prédios, que em sua maioria, é comercial, nos mais variados ramos de atividades. O fluxo de pedestres é contagiante nos dias de semana quando as pessoas estão em horários de trabalho e compras. A agitação toma conta dos comércios, agora em grande número pelas margens da avenida.

A construção e/ou reformulação dos prédios é bastante acentuada, assim como a adoção de espaços, onde os comerciantes vêm cuidando e ganhando direito de fixar placas luminosas de seu comércio, tornando-a mais bela, inclusive a maior concentração popular da cidade são realizadas ali, através de eventos políticos e culturais. Como exemplo, podemos citar as realizações de comemorações cívicas do calendário nacional e municipal, como outras manifestações públicas.

\footnotetext{
5 A autora desenvolve um estudo aprofundado sobre as práticas da modernidade que pretendo estar utilizando dentro do trabalho uma vez que esses estudos são fundamentais para a compreensão das práticas da sociedade pós-moderna.
} 


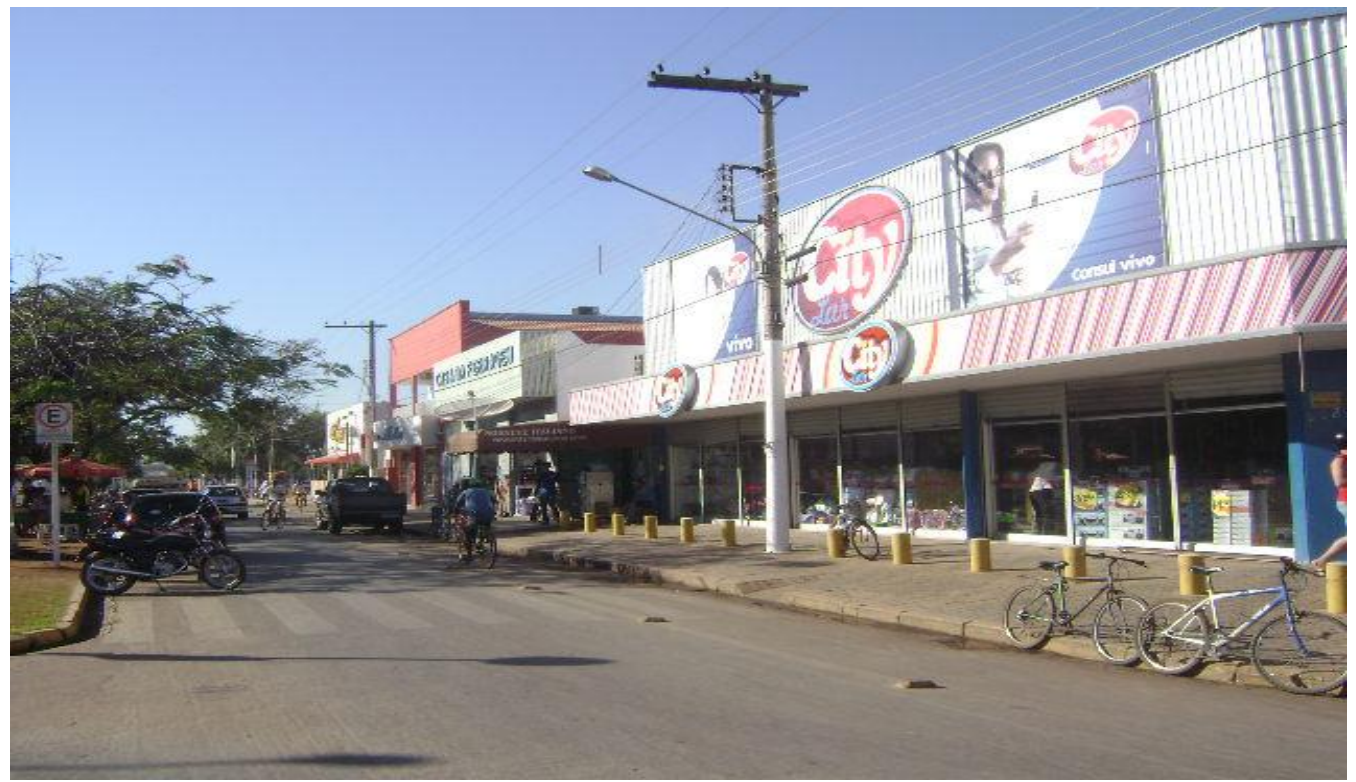

Foto 5 - A avenida Sete de Setembro hoje Fonte: Particular retirada em Março de 2013

Com um olhar mais aprofundado, podemos afirmar que a Avenida Sete de Setembro, na sua história, evolui da condição de uma via de rede na forma de caminho e trilha, para até momento chegar à condição de, se não a mais, uma das mais importantes, expressiva e significativa via urbana de Cáceres, guardando em seu passado lembranças, emoções e práticas sociais de diferentes contextos. A avenida e todo o seu contexto tornam-se parte importante para o imaginário da população local.

As mudanças ocorridas no espaço social da Avenida Sete de Setembro é um cenário das modificações socioculturais ocorridas no município de Cáceres. As atividades comerciais ganham um outro modelo, com vistas agora a atender as necessidades do mercado, com novas relações entre os trabalhadores e as novas tecnologias exigidas pelo mundo atual.

Observamos ao longo da avenida em um dia de semana a agitação que os transeuntes ocupam cada espaço do coração financeiro da cidade. Vidas, as mais diferentes entre si, transitam pelas calçadas, observam as lojas, procuram informações e estabelecem relações que desafiam a capacidade de penetrar esse universo envolto em cada espaço dessa parte importante da cidade.

\section{A AVENIDA SETE DE SETEMBRO: COMÉRCIO E COSUMIDORES}


A partir da Revolução Industrial do século XVIII, com a produção em série, o consumo de mercadorias no mundo inteiro cresce exponencialmente. Nas últimas décadas, como nos alerta Paula Sibília ${ }^{6}$, o capitalismo cumpriu seu destino já previsto por Karl Marx em O Capital sobre a mercantilização geral da sociedade. Segundo Sibília:

Há mais de um século depois da sua formulação, nesta época de ágeis mudanças o diagnóstico de Karl Marx a respeito do capitalismo parece estar atingindo o seu ápice, numa era em que o consumo rege todos os hábitos sócio-culturais.

Cremos que a Avenida Sete de Setembro reflete bem esta afirmação, pois se nós olharmos em traçado retilíneo perceberemos que o seu entorno está completamente tomado por empresas comerciais. Sendo assim, nesse momento tenho como objetivo analisar as mudanças que favoreceram a instalação destas empresas no local.

Em cada época o comércio, segundo uma lógica própria, se concentra nos lugares onde as pessoas transitam no seu dia-a-dia. No início do século XX, por exemplo, se situavam nos espaços compreendidos em torno da atual Praça Barão do Rio Branco e ao longo da margem do Rio Paraguai. Conforme Adson de Arruda ${ }^{7}$, nas três primeiras décadas do século $\mathrm{XX}$ :

percebe-se que as ruas, a praça e seus arredores não era apenas um
lugar público, cuja função era a circulação e o lazer dos habitantes da
cidade, ou seja, os usuários não se limitavam apenas em cumprir o
papel de passantes, ao desempenharem os rituais diários de
deslocamentos em direção aos armazéns, ao porto, ou outros lugares
menos "formais", construíam uma espacialidade marcada por uma
tensão entre normas e desvios.

Com o crescimento da cidade nas décadas de 1970 e 1980, a Sete de Setembro passou a fazer o papel de elo entre a "Grande Cavalhada" e bairros adjacentes - zona norte da cidade - e a região sul, constituindo-se assim num importante ponto de passagem de trabalhadores, estudantes, viajantes, etc.

Outro evento importante foi a pavimentação da avenida na década de 1970 o que propiciou um espaço importante para a instalação de lojas. Conforme o senhor João Batista vendedor de "churrasquinho" há mais de vinte anos na avenida":

Desde que comecei vender espetinho aqui nessa área da avenida, me lembro de quando as pessoas vinham das regiões vizinhas para

\footnotetext{
${ }^{6}$ SIBÍLIA, Paula. Op.cit. p. 36

${ }^{7}$ ARRUDA, Adson de. Op. Cit. p. 89

${ }^{8}$ Conforme o sr João Batista em entrevista realizada em março de 2013
} 
efetuarem suas compras reclamavam da distância que tinham que percorrer até o centro, onde se encontrava quase todo o comércio da cidade achavam muito longe, com o asfaltamento, outros comércios se deslocou para a avenida.

As modificações que presenciamos na cidade de Cáceres na década de 1970, representam todo um envolvimento de ações que contribuíram para o crescimento e fortalecimento da economia local, não obstante, podemos destacar que nesse período vamos ter também a construção da rodoviária no centro da cidade, na rua lateral esquerda à avenida, isso também pode ser considerado como um fato interessante para a mudança desse comércio como já foi citado anteriormente.

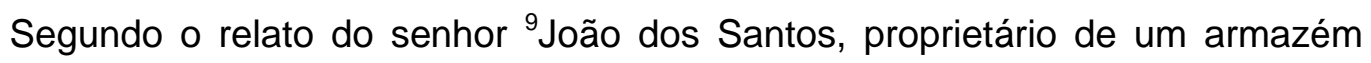
conhecido atualmente como "Mineiro", um dos comércios mais antigos da avenida é a loja onde se encontra a "Madeireira Madesul" antigo armazém "Paezano" em frente ao cemitério São João Batista

Destarte foi possível, perceber que com o passar do tempo a construção e/ou reformulação dos prédios foi bastante acentuada, assim como a adoção de espaços, onde os comerciantes vêm cuidando e ganhando direito de fixar placas luminosas de seu comércio. Vale ressaltar que inclusive a maior concentração popular da cidade está situada ali, o que podemos perceber através dos relatos do senhor Adilson Reis ${ }^{10}$ que nos informou que os principais eventos políticos e culturais da cidade são realizados no traçado da avenida, como exemplo, podemos citar as realizações de comemorações cívicas do calendário nacional e municipal, como outras manifestações públicas.

Com o conjunto de prédios erguidos as margens da Avenida Sete de Setembro, encontramos diferentes pontos comerciais, dentre os quais podemos destacar, Hospital, lojas de confecções, drogarias, lojas de calçados e os inconfundíveis camelôs. O corre-corre das pessoas pelas calçadas da avenida se mistura à correria do comércio e das atividades de um mundo marcado pela agitação das pessoas. Jacques Le Goff fazendo um estudo sobre a cidade medieval apontou alguns elementos que julgamos interessantes para nossa reflexão. Trata-se dos chamados " pontos quentes". Para ele "o que estrutura a cidade é um certo número de lugares (...) que determinam até certo ponto (...) a circulação" 11

Ao observar esses espaços urbanos bem como as multiplicidades das relações sociais que são desenvolvidas na cidade, podemos pensar a avenida em destaque

\footnotetext{
${ }^{9}$ Conforme o sr João dos Santos em entrevista realizada em março de 2013.

${ }^{10}$ Entrevista realizada em março de 2013

${ }^{11}$ LE GOFF, Jacques. O apogeu da cidade medieval. p 34
} 
Revista Eletrônica História, Natureza e Espaço - ISSN 2317-8361 v. 3, n. 1 (2014)

como um local de práticas e comportamentos distintos. A avenida, não por acaso, é localizada no centro da cidade podendo ser considerada como um ponto de referência comercial.

Um dado interessante que se pode constatar é a utilização maciça de upgrade tecnológico que grande parte das lojas teve que fazer para, ao mesmo tempo, racionalizar o tempo dos trabalhadores e atrair mais clientes. Segundo Ana Maria de Moraes ${ }^{12}$ trabalhadora há mais de vinte anos no comércio, a loja de confecções "Casa São Paulo" fez um investimento na área da informática, no layout da empresa, nas placas luminosas com o objetivo de torná-la mais atraente para o público.

A entrevistada argumenta que a loja teve que se enquadrar nesses avanços tecnológicos utilizados pelas lojas comerciais de grandes centros. Portanto, iniciou-se assim uma nova etapa na concorrência entre as empresas comerciais no município de Cáceres, incorporando outras práticas no cotidiano dos empresários locais.

Quanto aos consumidores estes tiveram que se adaptar ao novo sistema de compra e venda da loja em que os cartões de credito e débito são as principais formas de pagamento que a loja oferece. Segundo Marisol Melgar dos Santos ${ }^{13}$ estas novas tecnologias que tem por objetivo facilitar as transações comerciais e proporcionar maior segurança ao empresário terminam por estabelecer um novo aparelho de controle do qual é difícil escapar.

Podemos constatar que o comércio em Cáceres-MT, atualmente está na malha desse capitalismo moderno ou pós-industrial a qual alude Sibilia onde predomina a virtualização dos valores ${ }^{14}$, capitalismo este que, conforme já afirmamos anteriormente, atingiu seu ápice na sociedade atual em que o consumo rege todos os hábitos socioculturais, com o domínio absoluto do mercado em todas as esferas da sociedade.

Durante a pesquisa sobre a movimentação comercial da Avenida Sete de Setembro um dos entrevistados, proprietário de três lojas no ramo de confecções, nos relatou que atualmente o comércio da avenida está estagnado. Segundo ele seria preciso fazer uma parceria entre o poder público e o privado para o fortalecimento do comércio da avenida, pois segundo o mesmo Cáceres precisa de parceria entre esses dois órgãos para consolidar a sua economia local.

\footnotetext{
${ }^{12}$ Entrevista realizada em abril de 2013

${ }^{13}$ Santos, Marisol Melgar dos, Op. Cit. Capitulo Primeiro

${ }^{14}$ SIBÍLIA, Paula.Op.cit. p. 25.
} 
Pensar nessa parceria dos órgãos públicos com o comércio na Avenida Sete de Setembro em Cáceres é pensar o modelo capitalista e sua relação com o Estado. Historicamente a burguesia por mais que aderisse em massa ao liberalismo - laissez faire - nunca prescindiu da ajuda estatal para criar mecanismos legais, institucionais e logísticos para ampliar a acumulação de capital. Ralph Milibad ${ }^{15}$ fazendo uma reflexão sobre o fim dos regimes comunistas na Europa ocidental no final dos anos de 1990 afirma que uma das causas da derrocada daqueles regimes, particularmente na União Soviética foi a criação de uma burguesia que sempre viveu "à sombra" do Estado. Nesse sentido, tanto no liberalismo quanto no socialismo, o Estado tem o papel preponderante na acumulação de capital. Talvez seja por isso que Hannah Arendt tenha afirmado que a burguesia tomou o poder político em suas mãos a partir da expansão imperialista no final do século XIX quando o Estado-nação não mais atendia os seus interesses. ${ }^{16}$

Por outro lado, a inserção dos trabalhadores nesse capitalismo a que referimos anteriormente, é bastante problemática. Este tende a ser cada vez mais como uma peça descartável como qualquer outra mercadoria e isto atinge, de uma maneira ou de outra praticamente todas as camadas sociais. Sobre esse ponto Paula Sibília afirma que

As modalidades de trabalho também mudam e se expandem, tanto no espaço quanto no tempo. Abandonando o esquema dos horários fixos e das jornadas de trabalho estritamente delimitadas em rígidas coordenadas espaço-temporais, hoje surgem novos hábitos com ênfase nos contratos a curto prazo, na execução de projetos e na flexibilidade. ${ }^{17}$

Quando perguntamos sobre o aperfeiçoamento deles para trabalharem no comercio, é visível a cobrança para constantemente estarem buscando cada vez mais esse aperfeiçoamento através de cursos de capacitação. Richard Sennet aponta, da mesma forma que Sibília, que há uma tendência ao trabalho temporário, de curto prazo, superar o trabalhador fixo, sobretudo no comércio varejista. ${ }^{18}$

Vale lembrar que encontramos casos de comerciários que dedicam boa parte do seu tempo para satisfazer às necessidades desse capitalismo abordado por Sibília. A dedicação quase que integral às demandas exigidas pelo constante aperfeiçoamento transformam estes indivíduos em frequentadores assíduos de cursos

\footnotetext{
${ }^{15}$ Milibad, Ralph. Reflexões sobre a crise do regime comunista. In Robin Blackburn (org) Depois da queda, o fracasso do comunismo e o futuro do socialismo. p. 38

${ }^{16}$ ARENDT, Hannah. Origens do totalitarismo: Anti-Semitismo, imperialismo e totalitarismo. Livro dois capitulo um.

${ }^{17}$ SIBILIA, Paula. Op. Cit. p. 36.

${ }^{18}$ SENNET, Richard. A cultura do novo capitalismo. p. 50.
} 
Revista Eletrônica História, Natureza e Espaço - ISSN 2317-8361 v. 3, n. 1 (2014)

de capacitação e, o que é mais interessante, é que eles acreditam integralmente que este é o caminho correto. Porém, nem mesmo diante desta possibilidade o trabalhador está seguro, uma vez que a concorrência é muito acirrada.

Deleuze em um ensaio sobre o que ele denominou de "sociedade de controle" lembra-nos que o capitalismo mantém cerca de três quartos da humanidade em uma situação de extrema miséria, "pobres demais para a dívida", daí a explosão de guetos e favelas". ${ }^{19}$

A Avenida Sete de Setembro nesse contexto transforma-se em uma grande referência para o estudo das relações que envolvem a sociedade atual. Por meio das novas tecnologias de comunicação e informação nada escapa de um controle intenso sobre o consumidor e, ainda mais sobre o trabalhador.

Vale ressaltar que devido a esses fatos, a avenida tornou-se hoje, um dos espaços físicos mais usados pelos moradores da cidade, pois ali se encontra uma grande quantidade de prédios, que em sua maioria, é comercial, nos mais variados ramos de atividades. $O$ fluxo de pedestres é contagiante nos dias de semana quando as pessoas estão em horários de trabalho e compras. O movimento toma conta dos comércios, agora em grande número pelas margens da avenida.

Portanto, ao observamos essas transformações ocorridas ao longo da avenida podemos constatar que em um dia de semana a agitação toma conta dos comerciantes e usuários que ocupam cada espaço do traçado da avenida na cidade. Vidas, as mais diferentes entre si, transitam pelas calçadas, observam as lojas, procuram informações e estabelecem relações que desafiam a capacidade de penetrar nesse universo envolto dessa parte importante da cidade.

\section{CONSIDERAÇÕES FINAIS}

Maria Stella M. Brescianni, em História e historiografia das cidades um percurso, afirma que as cidades são, antes de tudo, uma experiência visual. Ruas cercadas de construções, igrejas e edifícios públicos. Mas ela é também movimento, animação, agitação de pessoas concentradas num mesmo espaço. Essa relação entre moradores e a arquitetura das cidades criam espaços saturados de significações acumuladas através do tempo. ${ }^{20}$

\footnotetext{
${ }^{19}$ DELEUZE, Gilles. Conversações. p.224.

${ }^{20}$ BRESCIANNI, Maria Stella M. Op. cit. p. 237
} 
Revista Eletrônica História, Natureza e Espaço - ISSN 2317-8361 v. 3, n. 1 (2014)

Nesse sentido, procurei fazer a minha pesquisa em relação à Avenida Sete de Setembro e formular um olhar diferente para as relações que permeiam as pessoas e os lugares desse espaço no centro da cidade. Acontecimentos e transformações ao longo do tempo nesse espaço urbano nos levaram a olhar as mudanças na sua estrutura física e social.

Mendes (1973:237-238) diz que a foram construídos mais de 600 metros de asfalto ao longo da avenida, com duas pistas e arborização. Dado esse que mostra uma transformação da cidade ao longo do tempo. Talvez, com o passar dos dias não notemos essas diferenças por que nos acostumamos com o cotidiano. Mas elas existem e são patentes ao visualizarmos as novas práticas que perpassam as pessoas envolvidas na avenida.

O desejo pela pesquisa surgiu através das discussões realizadas em sala de aula, e também pelo interesse de conhecer mais sobre essas transformações no espaço da Avenida. A reconstrução dos fatos que marcaram o desenvolvimento da Avenida Sete de Setembro nos possibilitou uma reflexão sobre a mesma, por isso ao olharmos essas mudanças não podemos deixar de refletir sobre o modo como vive a sociedade que a construiu, e assim discutir as novas formas de organização social que surgem com o avanço tecnológico.

Nesse sentido o comércio da Avenida Sete de Setembro atualmente possui essas características de modernidade que, ao longo do trabalho, e com as leituras dos autores consultados, pudemos perceber.

Essa experiência visual é que diferencia os diferentes olhares sobre o espaço estudado. O que há alguns anos era um caminho que levava ao cemitério e que poderia ser visualizado como um caminho para uma outra vida, hoje já não se é contemplada dessa forma. Na atualidade o que se nota é uma agitação que revela uma sociedade compenetrada em seus afazeres. A avenida tem as suas histórias e seus trajetos cheios de acontecimentos que podem ser problematizados de diferentes olhares.

A pesquisa serve para esclarecer os processos históricos e permite analisar, dentre outras coisas, a cidade-panorama de Certeau e o andar do pedestre por essa cidade: “... o espaço é um lugar praticado. Assim a rua geometricamente definida por um urbanismo é transformada em espaços pelos pedestres". (CERTEAU; 1994)

A intenção do trabalho foi problematizar essas transformações que aconteceram ao longo da história da avenida. Percebe-se que projetos urbanísticos para a avenida estão relacionados à ideia de progresso, característica que se encontra 
Revista Eletrônica História, Natureza e Espaço - ISSN 2317-8361 v. 3, n. 1 (2014)

ligada à necessidade de frequentes transformações. $E$ essas transformações continuaram a acontecer e deverão ser problematizadas com outros olhares e em outras situações.

\section{REFERÊNCIAS}

\section{FONTES}

\section{Fontes Escritas.}

Revista Cáceres Bicentenária (Edição Especial) Cuiabá Secretaria de Comunicação Social -MT, 1978.

Mendes, Natalino Ferreira. Efemérides Cacerenses. Vol I E II. Brasília: Gráfica do Senado, 1992.

Mendes, Natalino Ferreira. História de Cáceres, Cáceres: Carline \& Camiato, 1998.

\section{Fontes Orais.}

Adilson Reis

Ana Maria de Moraes

Miguel Senatore

Rosalvo Carneiro

\section{BIBLIOGRAFIA}

ARENDT, Hannah. Origens do totalitarismo: Anti-Semitismo, imperialismo e totalitarismo: Tradução Roberto Raposo. - São Paulo: Companhia das Letras. 1989

BRESCIANI, Maria Stella. História e historiografia das cidades, um percurso. Historiografia brasileira em perspectivas. (org) Marcos Cezar de Freitas. 4. ed. São Paulo: Contexto, 2001. p. 237-258.

CARLOS, Ana Fani Alessandri. O espaço urbano: Novos escritos sobre a cidade. 2 ed. São Paulo: Contexto, 2004.

CERTEAU, Michel de. A Invenção do Cotidiano - Artes de Fazer. 12. ed. ,Rio de Janeiro: Vozes, 1994. 
Revista Eletrônica História, Natureza e Espaço - ISSN 2317-8361 v. 3, n. 1 (2014)

DELEUZE, Gilles. Controle e devir; Post-Scriptum sobre as sociedades de controle. Conversações. Rio de Janeiro: Editora 34, 1992.

LE GOFF, Jacques. O apogeu da cidade medieval - São Paulo: Martins Fontes, 1992

MILIBAND, Ralph. Reflexões sobre a crise dos regimes comunista.In Robin Blackburn (org) Depois da queda, o fracasso do comunismo e o futuro do socialismo - Rio de Janeiro: Paz e Terra, 1992.

MONTENEGRO, Antonio Torres. História oral e Memória: A cultura popular revisitada. 3 ed. São Paulo :Contexto,1994

SENNET, Richard. A cultura do novo capitalismo - Rio de Janeiro: Record, 2006

SIBILIA, Paula. O homem pós-orgânico: corpo, subjetividade e tecnologias digitais. Rio de Janeiro: Relume Dumará, 2003

\section{MONOGRAFIAS, DISSERTAÇÕES E TESES}

ARRUDA, Adson de. Imprensa, vida e fronteira: A cidade de Cáceres nas primeiras décadas do século XX (1900-1930). Dissertação de Mestrado. Cuiabá, MT. UFMT. 2002.

SANTOS, Marisol Melgar dos. O comércio e o consumidor: A criação do CDL na visão do consumidor da cidade de Cáceres-MT na década de 1980. Monografia de Conclusão de Curso. Cáceres, MT. UNEMAT. 2005. 